\title{
STUDIES ON RED CELL DIAMETER
}

\section{In Health and in Pernicious Anemia}

By J. R. BELL, F. K. THOMAS, AND J. H. MEANS

(From the Medical Services of the Massachusetts General Hospital)

(Received for publication June 21, 1926)

During a visit to Guy's Hospital in the summer of 1924 one of us (J. H. M.) became interested in Hurst's (1) use of Price-Jones' method (2) of measuring the diameter of the red cells of the blood in cases of pernicious anemia, and was impressed not only with the possible importance of this procedure as a means of differentiating clinical types of anemia, but also with its possibilities as a method of investigating many problems in hematology. Accordingly measurements of this kind were promptly started at the Massachusetts General Hospital and have been in progress ever since. At the present time we are ready to report on a series of 20 normal persons and one of 25 cases of pernicious anemia.

\section{METHOD}

The method employed in this study is as follows. In a film of blood stained by Wright's stain 250 red cells are measured in their greatest horizontal diameter by means of an ocular micrometer which has been calibrated for a microscopic tube length of $170 \mathrm{~mm}$. by the use of a stage micrometer. With a mechanical stage it is easy to move the cells from right to left; only those falling directly beneath the scale are measured. With our scale it is possible to measure to every $0.66 \mu$ which is sufficiently accurate for the desired purpose. As it is possible that altitude, and perhaps other geographic factors may influence the size of red cells, it should be noted that all of the observations made by us were done in Boston, Massachusetts.

As the measurements are made a tally sheet is kept. When the desired total has been obtained, curves of either the frequency or summation type may be constructed from the data. Price-Jones (3) has used both types, but usually the former. We have rather preferred the latter, especially when plotted on Whipple's arithmetic probability paper, the advantage of it being that such a curve is 
more readily smoothed and lends itself more easily to comparing data of different observers, regardless of the number of cells measured or the size of the unit of measurement.

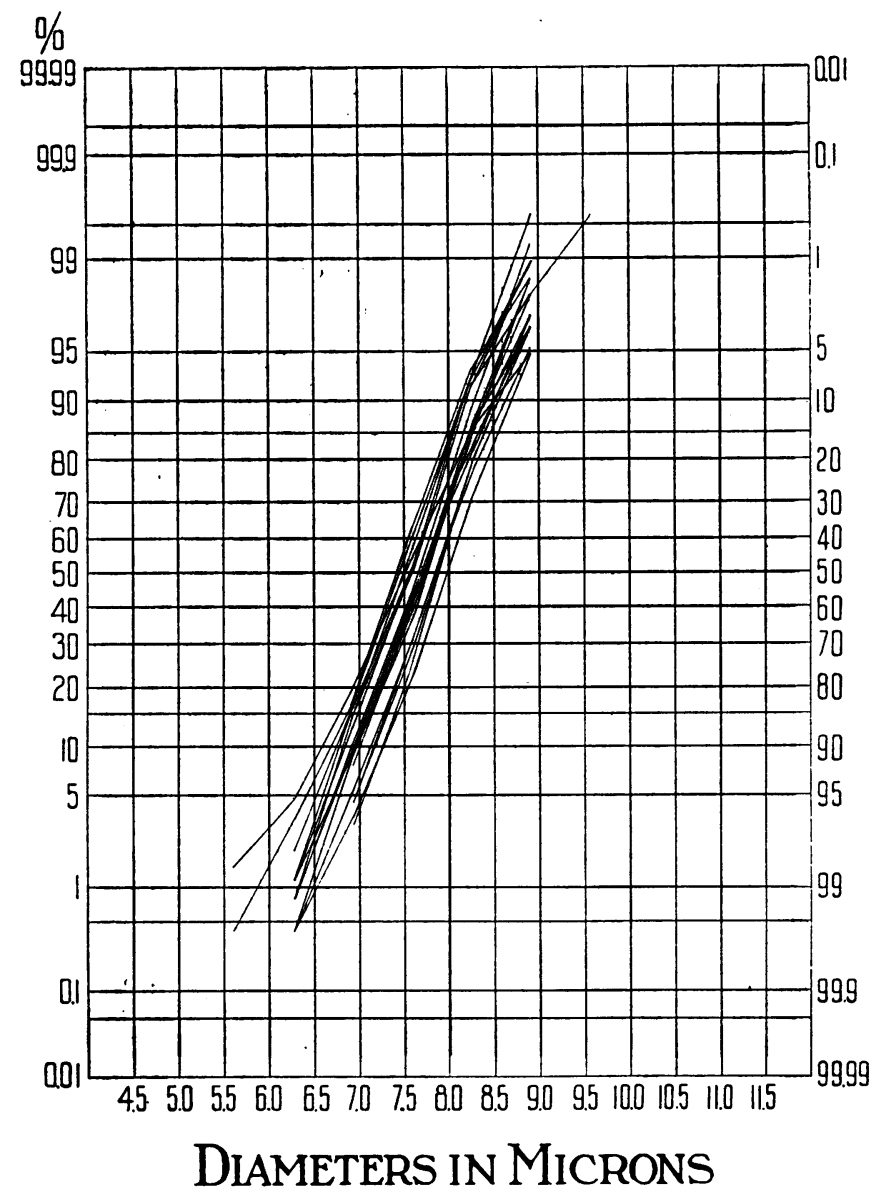

Fig. 1. Curves of Distribution of Red Cell Diameters in 20 Normal Persons, 10 Men and 10 Women

RESULTS IN NORMAL PERSONS

Films of blood from 20 normal persons between twenty and thirty years of age, 10 men and 10 women, were measured as described above. The curves obtained are shown in figure 1. Plotted on arithmetic 
probability paper any natural distribution yields approximately a straight line. Reference to figure 1 will show that the diameters of the red cells in our 20 normal subjects not only conform very closely to such a law, but also show a marked parallelism among the several members.

TABLE 1

Normal persons

\begin{tabular}{|c|c|c|c|c|}
\hline \multirow[t]{2}{*}{ Subject } & Sex & $\begin{array}{l}\text { Double disper- }- \\
\text { sion (84 }-16 \text { - } \\
\text { percentile) }\end{array}$ & $\begin{array}{c}\text { Median } \\
50 \text { percentile } \\
\text { grade }\end{array}$ & Mean \\
\hline & & microns & microns & microns \\
\hline C. T. . & F. & 1.1 & 7.7 & 7.6 \\
\hline M. M.. & F. & 1.0 & 7.7 & 7.7 \\
\hline V. B... & F. & 1.2 & 7.9 & 7.9 \\
\hline H. G. . & F. & 1.1 & 8.0 & 8.0 \\
\hline F.P. . & F. & 1.1 & 7.7 & 7.7 \\
\hline G. D... & F. & 1.1 & 7.9 & 7.8 \\
\hline M. R... & F. & 1.1 & 7.7 & 7.7 \\
\hline J. McI. & F. & 1.1 & 7.5 & 7.4 \\
\hline M. D.. & F. & 1.1 & 7.5 & 7.5 \\
\hline F. K. T. . & F. & 1.1 & 7.7 & 7.7 \\
\hline W. B.... & M. & 1.0 & 7.8 & 7.9 \\
\hline C. M. J. . & M. & 1.1 & 7.5 & 7.6 \\
\hline W. O.T. & M. & 1.2 & 7.8 & 7.7 \\
\hline D. B. D.. & M. & 1.0 & 7.9 & 7.8 \\
\hline D. R. H. . & M. & 1.1 & 7.7 & 7.7 \\
\hline C. W. H. . & M. & 1.1 & 7.5 & 7.5 \\
\hline J.S.L... & M. & 1.1 & 7.6 & 7.6 \\
\hline C. I. K... & M. & 1.2 & 7.4 & 7.4 \\
\hline S. $0 \ldots \ldots$ & M. & 1.1 & 7.7 & 7.7 \\
\hline G. W.T.............. & M. & 1.5 & 7.5 & 7.5 \\
\hline Average & 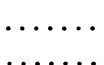 & $\begin{array}{l}1.1 \\
1.1\end{array}$ & $\begin{array}{l}7.7 \\
7.6\end{array}$ & 7.7 \\
\hline \multicolumn{2}{|l|}{ Grand average. . } & 1.1 & 7.7 & 7.7 \\
\hline
\end{tabular}

For purposes of comparison with pathologic bloods, or with normal bloods under unusual circumstances, we have, at the suggestion of Prof. E. B. Wilson, used the median (fifty percentile grade), and the sixteen and eighty-four percentile grades as taken from each individual curve. The median gives us the center of the range of dis- 
tribution of the red cell diameters, and the difference between the sixteen and eighty-four percentile grades gives double the dispersion. That is to say, in any given case the former shows whether the cell population as a whole tends to be of greater or less diameter than that of the usual normal, while the latter gives us a quantitative estimation . of the degree of anisocytosis. The values of these functions for our series of normals are given in table 1 , together with the mean diameter; this last being the function used by most other investigators. The medians and dispersions were read off from smoothed curves, the means were calculated from the tally sheets.

The table brings out several interesting points. First, with regard to the median we observe that the extreme variations in this function for the entire series is less than plus or minus 4 per cent of the average. Second, we note that between the sexes there seems to be no difference of importance; and third, between the medians and means of all there is a very close similarity, in fact the grand average for each of these functions is the same. The dispersions too show a high degree of consistency; with the single exception of G. W. T. the extreme variation being within plus or minus 9 per cent of the average for the entire series. Here again there is no significant difference between the sexes.

The object of this study of the blood of healthy persons, as already indicated, is to establish norms. To that end it would be desirable to plot frequency curves of the medians and dispersions, but the present series is not large enough to permit of that. It may be said, however, that measurements of the red cell population of 20 normal persons show a high degree of similarity; and that, in round numbers, the normal range for the median is between 7.4 and 8.0 microns, and for the dispersion 1.0 to 1.2 microns. Until such time as a large series of normal data is obtained, the foregoing will serve very well for normal values.

The extreme variation in red cell diameter should also be noted: in this series of twenty normals the smallest cell observed was 5.3 microns, the largest 9.9 microns. 
RESULTS IN PERNICIOUS ANEMTA

Data similar to those on normal persons have been collected on 25 cases of undoubted pernicious anemia. All the individual curves

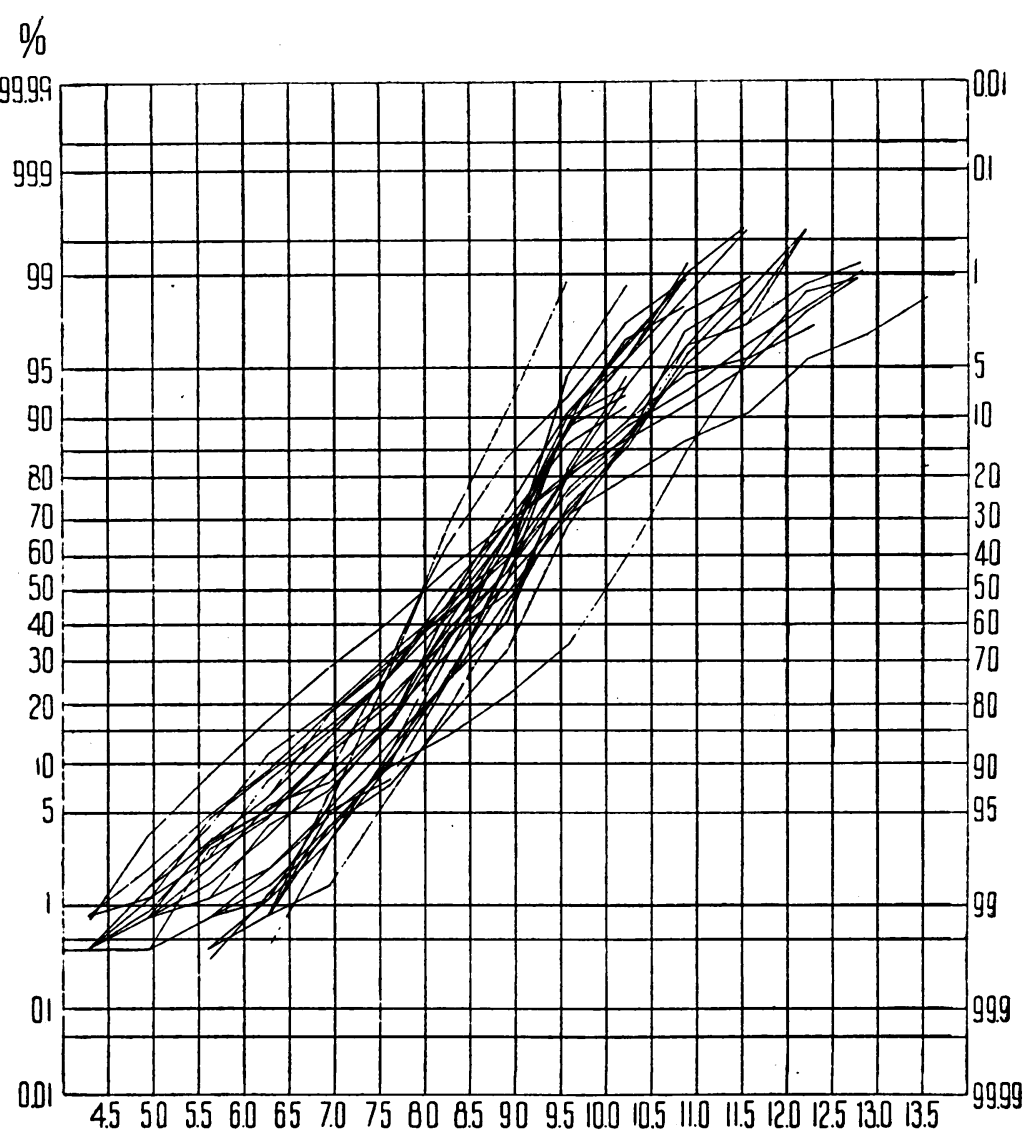

\section{DiAMETERS IN MiCRONS}

Fig. 2. Curves of Distribution of Red Cell Diameters in 25 Cases of Pernicious ANemia

are shown in figure 2, and the readings taken therefrom in table 2. Several striking departures from the normal series are obvious. For instance, not only the dispersion is greater (anisocytosis), but also the median definitely so. The average for the median in the 25 
pernicious anemia cases is 8.6 microns with a maximum of 10.0 microns (16 per cent above the average) and a minimum of 8.0 microns ( 7 per cent below the average). The average dispersion is

TABLE 2

Pernicious anemia*

\begin{tabular}{c|c|c|c}
\hline Patient & $\begin{array}{c}\text { Double dispersion } \\
\text { (84 and 16 percentile) }\end{array}$ & $\begin{array}{c}\text { Median } \\
\text { 50 percentile grade }\end{array}$ & Mean \\
\cline { 2 - 3 } 1 & microns & microns & microns \\
2 & 2.5 & 8.6 & 8.3 \\
3 & 3.2 & 8.5 & 8.4 \\
4 & 2.9 & 8.3 & 8.2 \\
5 & 2.4 & 10.0 & 9.8 \\
6 & 2.9 & 8.4 & 8.5 \\
7 & 1.4 & 8.7 & 8.6 \\
8 & 2.9 & 8.3 & 8.5 \\
9 & 2.5 & 8.4 & 8.3 \\
10 & 2.3 & 8.9 & 8.9 \\
11 & 1.7 & 9.0 & 8.9 \\
12 & 3.1 & 9.0 & 9.0 \\
13 & 1.5 & 8.8 & 8.8 \\
14 & 1.8 & 9.2 & 9.2 \\
15 & 1.7 & 9.0 & 8.9 \\
16 & 2.6 & 8.8 & 8.7 \\
17 & 1.8 & 8.7 & 8.6 \\
18 & 1.4 & 8.0 & 8.0 \\
19 & 2.8 & 8.7 & 8.7 \\
20 & 2.5 & 8.7 & 8.5 \\
21 & 3.6 & 8.0 & 7.9 \\
22 & 1.7 & 8.0 & 8.2 \\
23 & 1.6 & 8.6 & 8.6 \\
24 & 2.1 & 8.6 & 8.4 \\
25 & 1.8 & 8.5 & 8.4 \\
\hline Average......... & 1.7 & 8.4 & 8.2 \\
\hline
\end{tabular}

* Curves smoothed when possible.

2.3 microns with a maximum of 3.6 microns (plus 57 per cent) and a minimum of 1.4 (minus 39 per cent).

The mean in individual cases varies somewhat more from the median than in normal persons, but not to any significant degree. The greater divergence is due of course to the fact that these pernicious 
anemia curves are less symmetrical than those of the normal persons. In all but four instances it was not possible to smooth them, and the actual plot was used in taking off the readings.

The largest red cell found in pernicious anemia was 13.9 microns, the smallest 4.0 microns.

\section{DISCUSSION}

Since the discovery of the human red cells by Leeuwenhoek in 1673, measurements of their diameter have been made by numerous observers, their findings for the average diameter in normal blood ranging from 3.01 microns to 14.9 microns, with the major part of the observations for both wet and dry preparations lying between 7.5 and 8.0 microns. The literature on the micrometry of blood is so extensive and presents so many different methods of investigation that a separate paper will be devoted to its history.

However, in connection with our findings in normal blood, it seems fitting in this paper to call attention to the work of three other observers-one of fifty years ago, Richardson; the others of the present time, Ohno and Gievius. Richardson (4) in 1877 at the centennial celebration in Philadelphia obtained blood smears from representatives of fourteen different nationalities and from them made red cell diameter measurements. Fortunately in reporting his data he gives, besides the mean, two different percentile grades so it is possible to construct curves on arithmetic probability paper comparable to our own. Such curves for his findings are shown in figure 3. The similarity among the individual curves is marked, the medians ranging from 7.76 microns to 8.01 microns, and the dispersions from 0.57 microns to 0.77 microns. The former are in very close agreement with our findings, the latter are somewhat lower than ours; the fact that Richardson gives only two percentile grades from which we can construct curves might possibly be a factor in causing this difference. By this investigation Richardson has shown quite conclusively that there is apparently no significant difference in the bloods of different nationalities as far as red cell diameter is concerned.

In 1925 Ohno and Gievius (5) published their results of a very careful study on the diameter of human red blood cells. First, they measured red cells from four individuals, both in plasma and in dried 
smears, and found no significant difference between the two, the average for the diameter in plasma being 7.98 microns and in the smears 7.99 microns. Having found no difference in diameter between

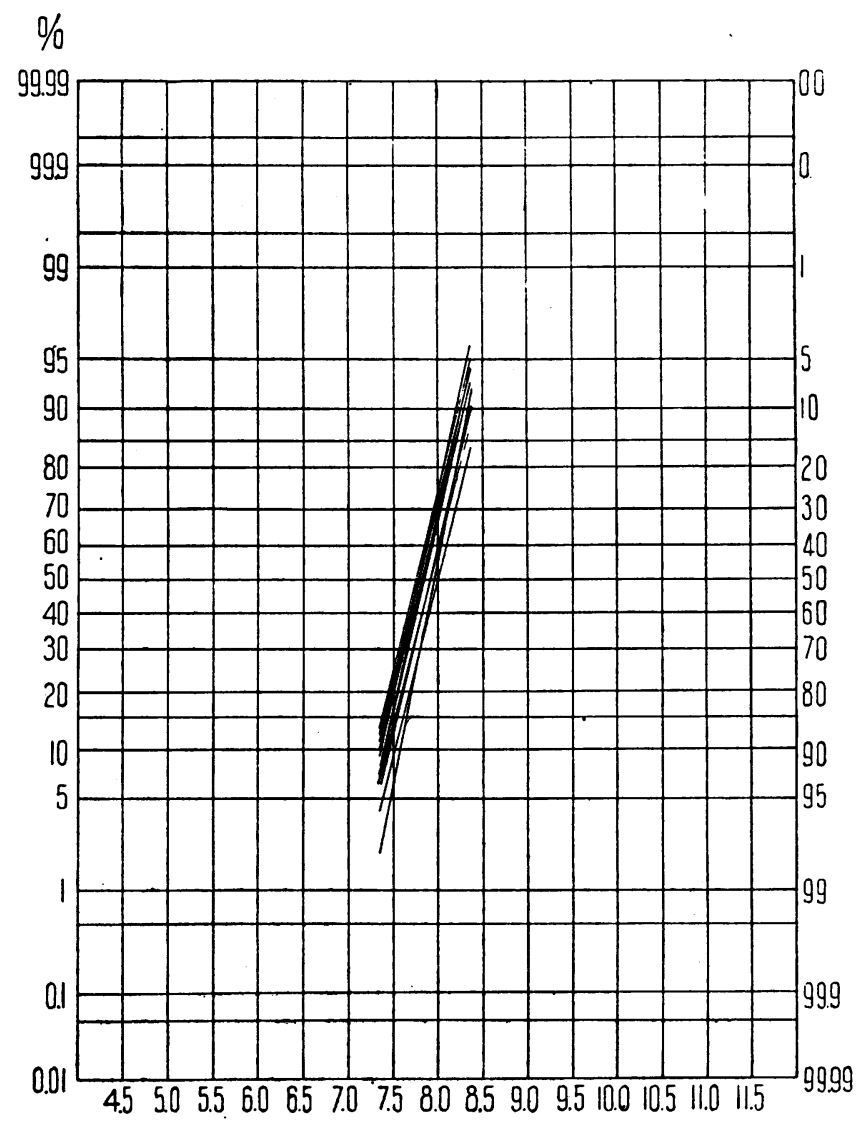

\section{DiAMETERS IN MiCRONS}

Fig. 3. Curves of Distribution of Red Cell Diameters in Individuals FROM FOURTEEN DIFFERENT NATIONS

(From Richardson, 1877)

the wet and dry method they then measured red cells in dried smears from 14 normal persons, 7 men and 7 women, reporting their results in tabular form showing the per cent of red cells lying within each 
0.25 micron from 6.00 microns to 9.99 microns. These data can be plotted on arithmetic probability paper giving the curves shown in figure 4. From these curves it will be seen that the median diameters

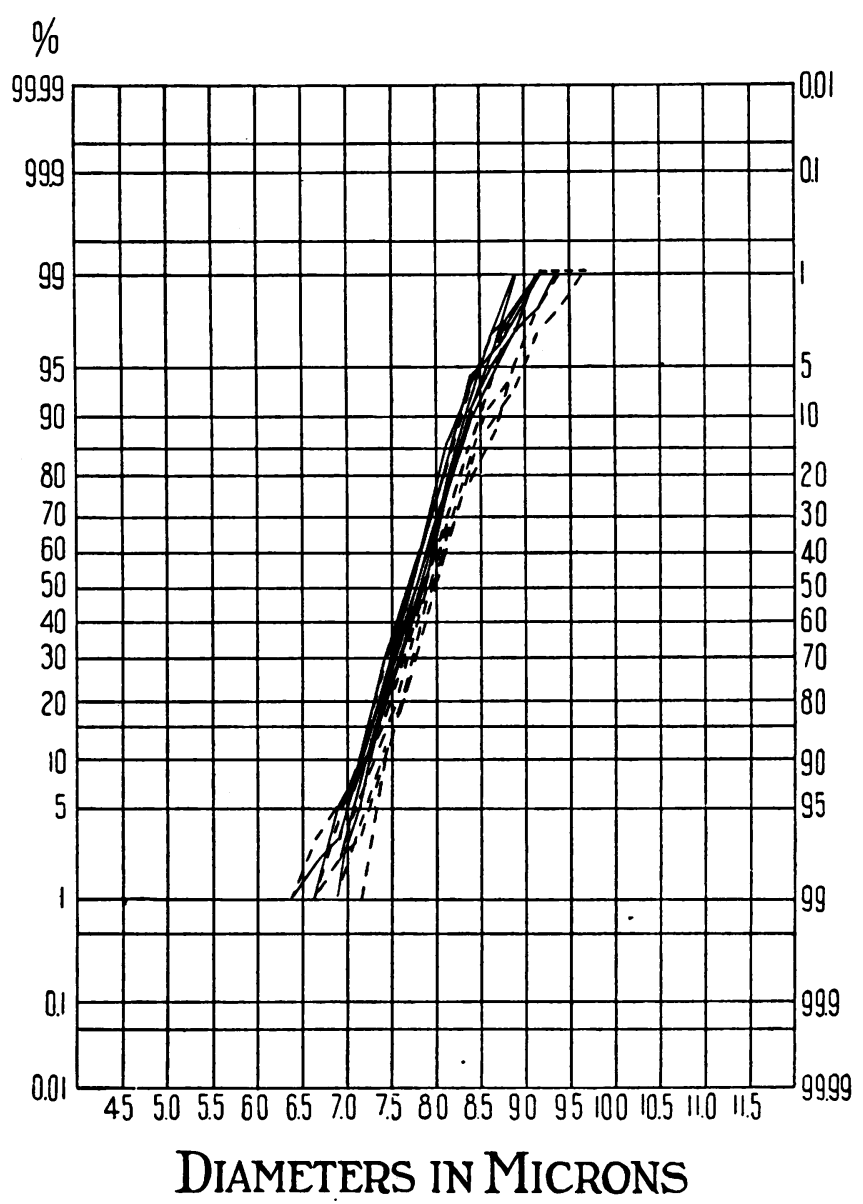

Fig. 4. Curves of Distribution of Red Cell Diameters in 14 Normai Persons, 7 Men and 7 Women

Men

(From Ohno and Gievius 1925.)

for women tend to run a little higher than those for men, the average for the former being 7.91 microns and for the latter 7.77 microns. The dispersion shows no appreciable difference for the two sexes. 
The average of 0.91 micron for the dispersion of the whole group is somewhat less than ours and is undoubtedly due to the fact that they found fewer microcytes than we did. In general, however, their findings are in very close agreement with ours.

Our work in cases of pernicious anemia also confirms the findings of others. Increased dispersion (anisocytosis) probably occurs in all anemias, but we agree with Price-Jones that increased dispersion plus increased mean diameter is highly characteristic, in fact these two might be said to be the characteristics of the red cells in pernicious anemia as far as diameter is concerned. Anemias other than pernicious may resemble it in these respects, but pernicious anemia seldom if ever fails to show these phenomena. For this reason Hampson and Shackle (6) have suggested that from the histologic point of view it would be best to divide all anemias into megalocytic and non-megalocytic rather than into primary and secondary. In the megalocytic group they would include the anemias of sprue and dibothriocephalus latus infestation.

Regarding the diagnostic significance of a distribution curve in differentiating between pernicious and other sorts of anemia, we agree with Hurst (1) that the finding of a normal or low mean diameter is very strong evidence against pernicious, or as he prefers to call it Addison's anemia. The average mean diameter in pernicious anemia found by Price-Jones (3) was 8.24 microns; by us 8.6 microns. The smallest and largest cell found by him were 3.75 microns and 12.25 microns respectively, and by us 4.0 microns and 13.9 microns.

It is of course desirable to learn the significance of the changes found in the blood of either pernicious anemia or other anemias. Why in pernicious anemia there should always be a high mean or median diameter, and in secondary anemia usually a normal or low one, is a question of great interest. Changes in mean diameter may result from physico-chemical changes in the blood, such as those produced by muscular work, forced breathing and alkali ingestion. From data of this sort Wiechmann and Schürmeyer (7) and PriceJones (8) conclude that mean diameter is dependent on blood reaction; a shift to the acid side causing an increase in diameter, a shift to the alkaline side, a decrease. Our observations on the diameter of red 
cells followịng strenuous muscular work agree with theirs. ${ }^{1}$ It is probable however that physico-chemical factors alone are not capable. of increasing dispersion significantly. Therefore, in the type of curve we use, rotation about the center in a clockwise direction denotes disturbance in blood formation or destruction, or both.

To interpret correctly the alterations found in any disease large numbers of data will have to be secured and correlations sought with a variety of other blood factors. Price-Jones (10) has already reported an absence of correlation between mean diameter and hemoglobin concentration of the blood or red count, but a definite correlation exists between both of these and dispersion in inverse ratio; that is to say, the severer the anemia, the greater the anisocytosis.

One thing that must be borne in mind is that whereas the red cell population of normal blood may follow a law of natural frequency, and therefore be a smooth curve, that of pernicious or other type of anemia may not. It may instead be a skew curve and represent a heterogeneous population. The study of the skewness of pathologic curves is therefore likely to yield information as to the nature of the changes occurring in blood disease. Difficulty will arise in distinguishing genuine from spurious skewness. In the counts of a relatively small number of cells the extremities of the curves denoting macrocytosis on the one hand and microcytosis on the other are based on such small numbers of observations that errors may be magnified, nevertheless with careful discrimination it should eventually be possible to recognize true skewness, or heterogeneity, and draw some conclusions on the probable significance of excess macrocytes or microcytes. Price-Jones (3) believes that in pernicious anemia there are probably three distinct populations: first, abnormally large cells which he calls "the pernicious element;" second, normal sized cells; and third, small cells due to the anemia resulting from extra blood destruction, "the anemia element." In many of our curves, as shown in figure 2, there is strong suggestion of genuine skewness indicating a heterogeneous population, perhaps of the sort Price-Jones suggests.

\footnotetext{
${ }^{1}$ Since the completion of this paper we have seen the results of determinations of red cell diameter after strenuous exercise published by Dryerre, Millar and Ponder (9). They report no change in size.
} 
The conclusions we have to draw at present are largely confirmatory of the work of others; they are as follows.

\section{CONCLUSIONS}

1. Diameters of the red cell population of the blood of normal persons follow the law of natural frequency.

2. The medians and dispersions of such curves are remarkably alike among different subjects.

3. In pernicious anemia there is a striking increase in both these functions.

4. This fact is of diagnostic significance in distinguishing between pernicious and other types of anemia.

We are greatly indebted to Prof. E. B. Wilson for many invaluable suggestions.

\section{BIBLIOGRAPHY}

1. Hurst, A. F.: Brit. Med. Jour., 1924, i, 93. Addison's (Pernicious) Anaemia and Subacute Degeneration of the Spinal Cord.

2. Price-Jones, C.: Brit. Med. Jour., 1910, ii, 1418. The Variation in the Sizes of Red Blood Cells.

3. Price-Jones, C.: Jour. Path. and Bact., 1922, xxv, 487. The Diameter of Red Cells in Pernicious Anaemia and in Anaemia Following Hemorrhage.

4. Richardson, J. G.: Am. Jour. Med. Sci., 1877, n.s., lxxiii, 112. On the Identity of the Red Blood Corpuscles in Different Races of Mankind.

5. Ohno, M., and Gievius, O.: Arch. f. d. ges. Physiol., 1925, ccx, 315 Schwankungsbreite und Schwankungsart der Durchmesser menschlicher Erythrocyten.

6. Hampson, A. C., and Shackle, J. W.: Guy's Hosp. Rep., 1924, lxxiv, 193. Megalocytic and Non-megalocytic Anaemias.

7. Wiechmann, E., and Schürmeyer, A.: Deutches. Arch. f. klin. Med., 1925, cxlvi, 362. Untersuchungen über den Durchmesser der roten Blutkörperchen.

8. Price-Jones, C.: Jour. Path. and Bact., 1920, xxiii, 371. The Diurnal Variation in the Sizes of Red Blood Cells.

9. Dryerre, H., Millar, W. G., and Ponder, E.: Quart. Jour. Exper. Physiol., 1926, xvi, 69. An Investigation into the Size of Human Erythrocytes Before and After Exercise.

10. Price-Jones, C., Guy's Hosp. Rep., 1924, lxxiv, 10. Anisocytosis with Special Reference to Pernicious Anaemia. 